\title{
Conditional Risk for PTSD among Latinos: A Systematic Review of Racial/Ethnic Differences and Sociocultural Explanations
}

\author{
Carmela Alcántara, Ph.D. ${ }^{1}$, Melynda D. Casement, Ph.D. ${ }^{2}$, and Roberto Lewis-Fernández, \\ M.D. ${ }^{3}$ \\ ${ }^{1}$ Department of Society, Human Development, and Health, Harvard School of Public Health, \\ Boston, MA \\ ${ }^{2}$ National Center for PTSD, at VA Boston Healthcare System and Boston University Medical \\ Center, Boston, MA \\ ${ }^{3}$ Department of Psychiatry, Columbia University and New York State Psychiatric Institute, New \\ York, NY
}

\begin{abstract}
Conditional risk for Posttraumatic Stress Disorder (PTSD)—defined as prevalence, onset, persistence, or severity of PTSD after traumatic exposure-appears to be higher among Latinos relative to non-Latinos after accounting for sociodemographic factors. This systematic review focuses on differences in conditional risk for PTSD between Latinos and non-Latinos (White, Black, or combined) and across Latino subgroups in studies that adjust for trauma exposure. We discuss methodological characteristics of existing articles and sociocultural explanatory factors. Electronic bibliographic searches were conducted for English-language articles published in peerreviewed journals between 1991 and 2012. We followed the Preferred Reporting Items for Systematic Reviews and Meta-Analyses guidelines. Twenty-eight articles met inclusion criteria. Consistent support was found for elevated rates of PTSD onset and PTSD severity among Latinos relative to non-Latino Whites. The evidence on racial/ethnic differences in conditional risk for PTSD prevalence and PTSD persistence is mixed. Twenty-four articles evaluated sociocultural explanations, with the strongest support found for racial/ethnic variation in peritraumatic responses and structure of PTSD. There were also consistent main effects for social disadvantage in studies that simultaneously adjusted for effects of race/ethnicity. Future research should use theoretically-driven models to formally test for interactions between sociocultural factors, race/ ethnicity, and PTSD probability.
\end{abstract}

\section{Keywords}

PTSD; Hispanics; immigrants; mental health; psychosocial risk factors; trauma

Posttraumatic Stress Disorder (PTSD) represents a major public health problem worldwide. PTSD is associated with significant role impairment (Alonso et al., 2011), increased risk of

\footnotetext{
(C) 2012 Elsevier Ltd. All rights reserved.

Correspondence concerning this article should be addressed to Carmela Alcántara now at Center for Behavioral Cardiovascular Health, Department of Medicine, Columbia University Medical Center; PH-9, Room 9-319; 622 West $168^{\text {th }}$ Street; New York, NY 10032.ca2543@columbia.edu; Phone: 212-342-5503.

Publisher's Disclaimer: This is a PDF file of an unedited manuscript that has been accepted for publication. As a service to our customers we are providing this early version of the manuscript. The manuscript will undergo copyediting, typesetting, and review of the resulting proof before it is published in its final citable form. Please note that during the production process errors may be discovered which could affect the content, and all legal disclaimers that apply to the journal pertain.
} 
suicidal behavior (Nock et al., 2009; Stein et al., 2010), and co-occurring physical health conditions and psychiatric disorders across developing and developed countries (Sareen, Cox, Clara, \& Asmundson, 2005). In the United States, the lifetime prevalence of PTSD differs slightly between Latinos $(4.4 \%-7.0 \%)$, non-Latino Whites $(6.5 \%-7.4 \%)$, and nonLatino Blacks (8.6\% - 8.7\%) (Alegría et al., 2008; Asnaani, Richey, Dimaite, Hinton, \& Hofmann, 2010; Roberts, Gilman, Breslau, Breslau, \& Koenen, 2010). These numerical differences in prevalence, however, are not always observed and usually not statistically significant (Breslau et al., 1998; Kessler, Sonnega, Bromet, \& Hughes, 1995). Yet, when focusing on differences in conditional risk for PTSD, defined as the risk of developing a PTSD diagnosis or PTSD symptoms, of endorsing more severe PTSD symptoms, or of experiencing more persistent PTSD over time, once exposed to one or more traumatic event(s), retrospective and prospective research suggests the conditional risk for PTSD is higher among Latinos than non-Latinos (White, Black, or combined comparison group).

To our knowledge, the earliest empirical articles to document higher conditional risk for PTSD among Latinos relative to non-Latinos were based on data obtained from the National Vietnam Veterans Readjustment Study (NVVRS, Kulka et al., 1990). The NVVRS was conducted between 1987 and 1988 and drew from a national probability sample of veterans and civilians. Kulka and colleagues' (1990) work showed that Latino male theater veterans had a higher point prevalence of PTSD than non-Latino Whites and Blacks more than a decade after the end of the Vietnam War, even after adjusting for war-zone stress and individual-level predisposing factors. Yet, several studies published since Kulka et al.'s seminal report in 1990 indicate these Latino and non-Latino White and Black differences in PTSD lose statistical significance after accounting for sociodemographic and trauma-related factors (e.g., pre-military and post-military socioeconomic status, trauma characteristics) (Dohrenwend, Turner, Turse, Lewis-Fernández, \& Yager, 2008; Lewis-Fernández et al., 2008). Other studies, by contrast, continue to document significant between-group variation in conditional PTSD risk among the NVVRS sample (Fontana \& Rosenheck, 1994; Ortega \& Rosenheck, 2000).

Prior reviews on racial/ethnic variation in PTSD prevalence have identified various sociocultural factors that may serve as potential mediators in the relationship between Latino ethnicity and PTSD. These include racial/ethnic variation in the tendency to experience a peritraumatic response, social disadvantage, cultural values of familism and fatalism, acculturation, differential expressive styles, structure of PTSD, and posttrauma coping (Pole, Gone, \& Kulkarni, 2008; Ruef, Litz, \& Schlenger, 2000). For example, some authors propose differences in adherence to culturally-based expressive styles or values such as familism and fatalism may influence endorsement patterns and coping responses, and subsequently affect PTSD estimates among Latinos. In particular, Latinos may over-endorse or over-report PTSD symptoms as a function of a cultural predisposition to amplify symptom experience during the experience itself, a tendency to report more symptoms subsequent to the experience despite the same level of resulting clinical severity, or to both kinds of expressiveness (Ortega \& Rosenheck, 2000; Ruef et al., 2000), which would result in elevated PTSD symptoms and prevalence rates. Furthermore, the extent to which Latinos relative to non-Latinos adhere to cultural values of fatalism (deterministic notions that the causal influence of external forces is greater than the causal influence of individual/internal forces), or familism (prioritization of interconnectedness among members of the family unit, and family priorities above individual priorities) (Laria \& Lewis-Fernández, 2006; Sabogal, Marín, Otero-Sabogal, \& Marín, 1987) may mediate coping styles and behavioral decisions to seek treatment. To this end, Latinos with greater adherence to these cultural values may be more likely to engage in passive coping and less likely to seek medical treatment or consult outside of the family system in the context of posttraumatic stress (Neff \& Hoppe, 1993; Perilla, Norris, \& Lavizzo, 2002). 
Extant reviews of racial/ethnic variation in PTSD are hampered by three major limitations. First, prior reviews focused narrowly on specific subsamples (e.g., Vietnam veterans in the NVVRS) or did not adjust for trauma exposure. Second, within-Latino group differences in PTSD were never explored. Third, the role of sociocultural factors in Latino and non-Latino differences in PTSD probability was not examined systematically. Hence, whether there are true differences between Latinos and non-Latinos (and across Latino subgroups) in the risk of developing and/or maintaining PTSD after adjusting for differential rates of trauma exposure remains unclear. Moreover, much less is known about potential sociocultural factors that could contribute to this variation in conditional risk for PTSD across Latino subgroups and between Latinos and non-Latinos (for brief reviews see Hinton \& LewisFernandez, 2011; Pole et al., 2008).

Herein, we conduct a systematic review of the literature on Latino and non-Latino differences in conditional risk for PTSD in order to: (a) summarize the methodological characteristics of included articles, (b) evaluate the methodological quality and risk of bias within and across selected articles, (c) examine the extent to which there are consistent differences between Latinos and non-Latinos (White, Black, or Combined) and across Latino subgroups in conditional risk for PTSD as assessed across a range of PTSD indicators, and (d) identify and describe tested sociocultural explanatory factors.

We focus our review on Latino and non-Latino between-group differences and withinLatino group differences in conditional risk for PTSD, although we acknowledge that most of the literature provides comparisons between Latinos and non-Latino Whites and only occasionally includes non-Latino Blacks and other non-Latinos. Our review distinguishes between articles on overall prevalence of PTSD and those that focus on PTSD severity. In addition, we differentiate between onset and persistence of PTSD as a way of capturing two aspects of PTSD course that affect estimates of prevalence (Dohrenwend et al., 2008;

Tsuang, Tohen, \& Zahner, 1995). We limit our review to articles that account for the effect of trauma exposure, and thereby enable exploration specifically of the conditional risk for PTSD, not only of unadjusted estimates of differential PTSD probability across racial/ethnic categories.

\section{Methods}

\section{Article Selection}

Our systematic review followed the guidelines offered in the Preferred Reporting Items for Systematic Reviews and Meta-Analyses (PRISMA; Liberati et al., 2009; Moher, Liberati, Tetzlaff, Altman, \& The, 2009). To ensure a transparent and accurate report, the PRISMA Statement provides a four-phase flow diagram and a 27 -item checklist that assesses each major section in a systematic review. Herein, we report information on 25 of these items; two items are not discussed because they instruct authors to describe methods of additional analyses (item \#16) and give results from additional analyses such as meta-regression, sensitivity or subgroup analyses (item \#23).

We searched the PsycINFO and PubMed bibliographic databases for research articles on PTSD and Latinos published in peer-reviewed journal articles between 1991 and 2012 and written in English. The broad search terms included "Hispanic/Latino" AND "PTSD". We also conducted manual searches of the reference sections of articles and book chapters that were identified through bibliographic database search and met review inclusion criteria. The year 1991 was chosen as a reference point because our purpose was to examine journal articles that were available after the publication ofKulka et al. (1990), particularly because prior to 1990 most studies did not systematically examine racial/ethnic group differences in PTSD probability. 
Eligible articles had to: (a) focus on adults, (b) report outcomes for PTSD diagnosis or PTSD symptoms, (c) account for trauma exposure, and (d) include a between-group analytical design (e.g., Latinos vs. non-Latino Whites, non-Latino Blacks, or non-Latinos in general) or a within-Latino group analytical design (e.g., Spanish-speaking vs. Englishspeaking Latinos). We limited our review to research that accounted for the effect of trauma exposure (either directly as an independent variable or indirectly by comparing groups that did not differ in trauma exposure) to facilitate exploration specifically of the conditional risk for PTSD.

\section{Data Collection Process and Data Items}

The first two authors screened all articles for eligibility; their concordance in article selection was excellent, as evidenced by kappa $=.86$. Disagreement occurred in six cases and was resolved by consensus. Information was extracted from each article on characteristics of the study including: (1) percentage female, sample size, data source/ setting, index trauma; (2) outcome (PTSD prevalence, onset, persistence, or severity); (3) measure used to assess PTSD and whether differences were statistically significant; and (4) sociocultural explanations tested and whether results were statistically significant.

We classified articles according to the PTSD outcome of interest (i.e., prevalence, onset, persistence, and severity). Articles on PTSD prevalence focused on the overall proportion or number of cases in a given time period (either lifetime or current). We included articles that measured PTSD prevalence with clinician-administered diagnostic interviews, layadministered structured diagnostic interviews, or self-report symptom checklist and cutoff scores. Articles that relied on self-report symptom checklists and cutoff scores derived estimations of PTSD prevalence by inferring a probable PTSD diagnosis. We note that articles that examined probable PTSD in relation to multiple traumas (i.e., a single index trauma and a worst lifetime trauma) were classified under the general subheading of PTSD Prevalence because the onset of PTSD could not be assigned to a particular traumatic event. Articles on PTSD Onset included those that documented new cases of PTSD that were explicitly linked to an index trauma. Articles on PTSD Persistence included those that examined maintenance of a PTSD diagnosis or PTSD symptoms after adjusting for prior history of PTSD. Lastly, the subheading of PTSD Severity included any articles that assessed symptom counts, either overall or by symptom cluster, usually from a symptom checklist. To facilitate organization, we report first findings on Latino and non-Latino group (White, Black, or Combined) differences in the Between-Group section. Next, we report findings across Latino subgroups in the Within-Group subsection. In cases where articles discuss both between-group and within-group differences, we discuss relevant findings across Latino subgroups in the Within-Group subsection and findings on racial/ethnic differences in the Between-Group subsection, such that articles may be referenced in more than one subsection.

In regard to sociocultural factors, we assessed the extent to which articles examined between-group and Latino subgroup variation in conditional risk for PTSD as a function of seven sociocultural factors identified in the literature: acculturation, expressive style, structure of PTSD, peri-traumatic responses, coping, cultural values of familism and fatalism, and social disadvantage. We report findings on these sociocultural factors under the Sociocultural Explanations section. Indicators of social disadvantage refer to attributes that are used to group people according to social hierarchies such as socioeconomic status and race/ethnicity, or conditions of relative or absolute deprivation (e.g., poverty, health insurance) including racism (Braveman \& Gruskin, 2003). We describe articles that test for an independent effect of ethnicity and at least one of the aforementioned sociocultural factors in PTSD conditional risk models that adjust or account for trauma exposure, as well as those that test for moderation and mediation effects. 


\section{Methodological Quality and Risk of Bias Assessment}

We used the Cochrane Risk of Bias assessment tool as discussed in the Cochrane Handbook for Systematic Reviews of Interventions (Higgins \& Green, 2011) to assess the risk of bias in selected articles. We focused on three indicators of risk of bias that were most pertinent to the analysis of non-clinical trial data, including selection bias due to inadequate generation of a randomized sequence, attrition bias due to the amount, nature, or handling of incomplete outcome data, and reporting bias due to selective outcome reporting. We rated whether included articles exhibited low risk, high risk or unclear risk across the three bias domains (selection bias, attribution bias, and reporting bias) according to the criteria for judging risk of bias discussed in the Cochrane assessment tool (Higgins \& Green, 2011). To calibrate our evaluation process for assessing risk of bias, we completed and discussed ratings on seven randomly selected articles that did not meet inclusion criteria. We achieved adequate reliability once we reached consensus on ratings across the three bias domains. Next, the first two authors worked independently to ascertain risk of bias for each included article. We calculated an overall kappa coefficient to determine inter-rater reliability for the risk of bias assessment across the three domains. The first two authors exhibited substantial agreement (kappa $=.64)$. Differences in risk of bias assessment ratings emerged for the attrition bias and selection bias domains and were resolved through consensus; there was perfect agreement for the reporting bias ratings.

\section{Results}

\section{Article Selection}

Our initial bibliographic database search yielded 133 articles. Based on the eligibility criteria, 105 articles were excluded. Sixteen articles were case studies or focused on treatment, utilization, or access to services, 28 did not examine PTSD or PTSD symptoms as outcomes of interest, 12 were focused on children/adolescents, 15 did not include betweengroup or within-group analytic comparisons or did not analyze racial/ethnic-group differences, 3 did not include a Latino group, 6 were reviews or commentaries, one had an international focus and did not include a US comparison sample, and 24 did not adjust for the effect of trauma exposure. Thus, our final sample included 28 articles (see Figure 1).

\section{Article Characteristics}

Table 1 displays the study characteristics for the 28 articles that met review inclusion criteria. The sample sizes ranged from 11 to 3,651 for the Latino group and 70 to 14,911 for the comparison group. The percentage of female participants ranged from $0 \%$ to $100 \%$ (median $=41.05)$. Most articles $(n=23)$ assessed trauma related to a specific index event type, including combat (largely in the Vietnam War) $(n=7)$, World Trade Center (WTC) attack $(n=7)$, police duty $(n=2)$, physical injury $(n=4)$, and hurricanes $(n=3)$. Five articles examined PTSD associated with exposure to more than one index traumatic event, including exposure to childhood emotional, physical, or sexual abuse $(n=1)$, intimate partner violence $(n=2)$, or multiple lifetime traumatic events $(n=2)$. There was variation in the quality and scope of the adjustments made for trauma exposure. Most articles used proxy measures of exposure (e.g., number of days hospitalized, distance from epicenter of disaster, injuries incurred, involved in rescue efforts) and tended not to include subjective measures of trauma exposure, severity, and subsequent distress.

Fifty percent of the articles conducted assessments in Spanish. However, the number of participants interviewed in Spanish was very small (.01\%-.04\% of participants in epidemiological surveys). Most articles used symptom checklists or lay-administered diagnostic interviews to estimate probable PTSD prevalence, onset, persistence, or severity $(n=25)$. The most commonly used measure to assess PTSD symptoms was the PTSD 
Checklist-Civilian version $(n=7)$, followed by the National Women's Study PTSD module $(n=5)$. Only three articles used a clinician-administered semi-structured diagnostic instrument (Dohrenwend et al., 2008; Lewis-Fernández et al., 2008; Schnurr, Lunney, \& Sengupta, 2004).

Most of the literature examined differences in PTSD prevalence $(n=11)$ and PTSD severity $(n=12)$. Articles that examined PTSD prevalence differed on the time period assessed (i.e., 30-day, 6-month, 12-month, or lifetime prevalence). Three of the 11 articles classified under PTSD Prevalence examined PTSD symptoms after exposure to the events of 9/11, but assessed PTSD symptoms in reference to the WTC attack as well as respondents' "most stressful traumatic event"; thus estimations of PTSD refer to probable PTSD prevalence and not PTSD onset. Fewer articles disaggregated PTSD onset $(n=8)$ from PTSD persistence $(n$ $=5$ ). We note that five articles examined PTSD onset in relation to the WTC attack or Hurricane Andrew/Hurricane Paulina and in these cases assessed whether content-specific symptoms (e.g., intrusions) were related to the index trauma; however, symptoms that were not content-specific (e.g., hyper-arousal symptoms) were not assessed in reference to the index trauma.

Twenty-six of the twenty-eight articles examined Latino and non-Latino between-group differences in conditional risk for PTSD. Most included a non-Latino White $(n=21)$ comparison group, followed by non-Latino Black comparison group $(n=8)$, and a combined non-Latino group $(n=3)$. Six included more than one comparison group and three reported differences both between Latinos and non-Latinos and across Latino subgroups. Two articles examined only Latino within-group differences, including the effect of nativity (Heilemann, Kury, \& Lee, 2005) and language (Rodriguez et al., 2008) on prevalence of probable PTSD.

\section{Methodological Characteristics and Risk of Bias Assessments}

Most articles (Table 2) drew from non-random samples $(n=16 ; 57 \%)$ resulting in high selection bias ratings, while the remaining 12 articles (43\%) exhibited low risk of selection bias. All articles were rated as low risk of reporting bias due to minimal threats to selective outcome reporting. Ratings of attrition bias were much more mixed across articles. For example, eleven articles (39\%) were rated low risk of attrition bias, five (18\%) were rated high risk of attrition bias, and 12 (43\%) were rated unclear risk due to insufficient reporting of attrition and exclusions that made it impossible to determine whether the article exhibited low risk or high risk for attrition bias. Seven articles had the lowest risk of bias across the three bias domains, thereby representing the highest-quality articles (Dohrenwend et al., 2008; Galea et al., 2008; Galea et al., 2004; Lewis-Fernández et al., 2008; Ortega \& Rosenheck, 2000; Roberts et al., 2010; Schlenger, Kulka, Fairbank, \& Hough, 1992). Of these, nearly all referred to combat in the Vietnam War $(n=4)$ and to exposure to the World Trade Center attack $(n=2)$ as the index trauma; one article assessed exposure to multiple traumatic events.

\section{Between-Group Differences in Conditional PTSD}

PTSD Prevalence-Six out of 11 articles on PTSD prevalence reported statistically significant differences in conditional risk for PTSD, suggesting that once Latinos are exposed to a traumatic event, they are significantly more likely to meet criteria for probable PTSD than non-Latino Whites and Blacks (Bowler et al., 2010; Fontana \& Rosenheck, 1994; Lewis-Fernández et al., 2008; Ortega \& Rosenheck, 2000; Schlenger et al., 1992; Stampfel, Chapman, \& Alvarez, 2010). Articles reporting significant differences in prevalence of probable PTSD assessed PTSD within the past month or six months. Support for significant differences in prevalence of probable PTSD between Latinos and non-Latino 
Whites was found for exposure to the Vietnam War $(n=4)$ and the WTC attack $(n=1)$; differences between Latinos and non-Latino Blacks were found for exposure to interpersonal violence $(n=1)$ and the Vietnam War $(n=1)$.

Of the five articles that reported non-significant differences, four assessed whether respondents met criteria for probable PTSD during the past 12 months or lifetime (Adams \& Boscarino, 2005; Adams \& Boscarino, 2006; Roberts et al., 2010; Rodriguez et al., 2008; Zatzick et al., 2007). The fifth study that reported non-significant differences used a clinician-administered diagnostic interview (Lewis-Fernández et al., 2008).

Using data from the NVVRS, three articles (Fontana \& Rosenheck, 1994; Ortega \& Rosenheck, 2000; Schlenger et al., 1992) reanalyzed the data first presented by Kulka et al. (1990) to show that Latino male Vietnam theater veterans exhibited elevated rates of current PTSD relative to non-Latino White male veterans using multivariable regression models or structural equation modeling; no significant differences were reported between Latinos and non-Latino Blacks after adjustment for trauma exposure. Ortega and Rosenheck (2000) were one of the first to examine differences across Latino subgroups and between these subgroups and non-Latino Whites, finding that both Puerto Rican and Mexican American veterans had elevated rates of PTSD compared to non-Latino White veterans after adjusting for premilitary (e.g., educational attainment, childhood poverty) and military factors (e.g., degree of war zone experience). In a subsequent article, Lewis-Fernández et al. (2008) found that elevated rates of PTSD in the NVVRS among Latinos relative to non-Latino Whites and Blacks were only observed when comparing probable PTSD diagnoses based on self-report symptom checklists, but not when comparing actual PTSD diagnoses made with clinicianadministered diagnostic interviews. This suggests that clinician-administered diagnostic interviews may correct for between-group variation in endorsement patterns that may contribute to differential responding to PTSD self-report questionnaires. Elevated rates of probable PTSD have also been observed in Latino male police first responders relative to non-Latino White males during the two-to-three year period after the WTC attack (Bowler et al., 2010), and among Latino women relative to non-Latino Black women exposed to interpersonal violence (Stampfel et al., 2010).

PTSD Onset, PTSD Persistence-Six out of the 8 articles that examined PTSD onset reported that Latinos were more likely than non-Latino Whites, Blacks, or a combined nonLatino group to meet criteria for PTSD onset associated with the index traumatic event (DiGrande et al., 2008; Galea et al., 2002; Galea et al., 2004; Norris, Perilla, Ibañez, \& Murphy, 2001; Perilla et al., 2002; A. E. Williams et al., 2008). In particular, a higher rate of probable PTSD onset was observed among Latinos relative to non-Latino Whites or the combined non-Latino group at five to eight weeks following the WTC attack (Galea et al., 2002), six months after the attack (Galea et al., 2004), and two to three years after the attack (DiGrande et al., 2008). Similarly, elevated rates of probable PTSD onset were observed among Latino survivors of physical trauma relative to non-Latino Whites less than three months after musculoskeletal injury (A. E. Williams et al., 2008).

The other two articles reporting significant differences in PTSD onset involved hurricane exposure and found significant gender-by-ethnicity or exposure-by-ethnicity effects on estimates of probable PTSD onset. For example, an article on PTSD onset 6 months after Hurricane Paulina in Mexico and Hurricane Andrew in southern Florida found elevated rates of PTSD among Mexican women relative to non-Latino Whites, but did not document an independent effect of Mexican ethnicity on PTSD (Norris, Perilla, Ibañez, et al., 2001). Furthermore, higher PTSD onset was documented among Spanish-speaking Latinos relative to non-Latino Whites and Blacks, but only among those who perceived a high degree of personal life threat or injury and those who lived in a neighborhood with a high proportion 
of reported personal trauma as a result of Hurricane Andrew (Perilla et al., 2002). This is suggestive of an interaction between social disadvantage and Latino ethnicity that is particularly influential on estimates of PTSD risk among vulnerable communities. We note that the remaining two articles that did not find significant differences in PTSD onset involved exposure to combat in the Vietnam War and used clinician-administered diagnostic assessments of PTSD (Dohrenwend et al., 2008; Lewis-Fernández et al., 2008).

The five articles that examined PTSD persistence drew from longitudinal data on the longstanding posttraumatic effects of the WTC attack and participation in combat. Two articles found that Latinos were more likely to exhibit PTSD persistence than non-Latino Whites and Blacks (Adams \& Boscarino, 2006; Galea et al., 2008). For example, in a population-based prospective study after the WTC attack of a representative sample of 2,752 NYC residents, Latino ethnicity was consistently associated with PTSD at each of three time points over a two-year period in multivariate analyses (Galea et al., 2008) and at two to three years post-9/11 among a representative sample of Manhattan residents living south of Canal Street (Adams \& Boscarino, 2006). Galea and colleagues (2008) adjusted for the effect of respondents' peri-event emotional reaction (i.e., endorsement of panic symptoms in the hours following the WTC attack), and whether respondents were directly affected by $9 / 11$ (i.e., injured during attack, lost possession or property, friend/relative killed, involved in rescue effort, or lost job as a result of attack). In contrast, Schnurr and colleagues (2004) found that Latino ethnicity among male Vietnam veterans was not associated with persistence of PTSD.

It is notable that the two articles that failed to find significant differences in PTSD onset (Dohrenwend et al., 2008; Lewis-Fernández et al., 2008) and the three that did not find a significant effect of Latino ethnicity on persistence of PTSD (Dohrenwend et al., 2008; Lewis-Fernández et al., 2008; Schnurr et al., 2004) used clinician-administered semistructured clinical interviews to assess PTSD symptoms rather than self-report measures.

PTSD Severity-Eleven out of 12 articles that examined PTSD symptom severity reported a significant effect of Latino ethnicity (Balsam, Lehavot, Beadnell, \& Circo, 2010; Denson, Marshall, Schell, \& Jaycox, 2007; Heilemann et al., 2005; Koopman et al., 2001; LewisFernández et al., 2008; Marshall, Schell, \& Miles, 2009; Norris, Perilla, Ibañez, et al., 2001; Norris, Perilla, \& Murphy, 2001; Ortega \& Rosenheck, 2000; Pole, Best, Metzler, \& Marmar, 2005; Pole et al., 2001). All but one study (Denson et al., 2007) indicated that Latinos reported greater symptom severity than their non-Latino counterparts. Eight of the 12 articles come from research with urban police officers or survivors of intimate partner violence, physical injury, hurricanes, and childhood abuse. For example, Pole and colleagues $(2005 ; 2001)$ showed that Latino urban police officers endorsed elevated PTSD symptoms relative to non-Latino White and Black officers after adjusting for the effect of their most disturbing police-related critical incident, social desirability, and peri-traumatic dissociation. There were no significant differences by ethnicity in exposure to duty-related critical incidents in this sample; however, the authors did not account for differences in any non-duty/police related trauma exposures, including childhood trauma, which may have contributed to ethnic differences in PTSD symptoms.

Latino ethnicity was also significantly associated with PTSD severity in a sample of Latino (mostly Mexican) survivors of physical injury when assessed prospectively for posttraumatic symptoms within days, 6 months, and 12 months post-trauma (Marshall et al., 2009). The elevated PTSD severity found among Latinos relative to non-Latino Whites persisted over time, even when the ethnic groups were matched by type and severity of trauma exposure using propensity weights; there were no significant differences in PTSD severity between Latinos and non-Latino Blacks. In contrast,Denson et al. (2007) found that 
Latino ethnicity was associated with decreased PTSD symptom severity in a sample of community violence survivors.

Articles on PTSD severity and combat exposure have examined racial/ethnic between-group variation across a range of severity indicators. For example,Koopman et al. (2001) found a significant relationship between Latino ethnicity and acute dissociative reactions that are consistent with symptoms in the PTSD re-experiencing cluster. Furthermore, articles on elevations in specific PTSD symptom clusters found that Mexicans living in Mexico relative to a non-Latino sample in the US scored higher on symptoms of the avoidance and intrusion (re-experiencing) symptom clusters (Norris, Perilla, \& Murphy, 2001). Lewis-Fernández and colleagues (2008) examined between-group variation in PTSD severity in addition to PTSD prevalence in the NVVRS subsample interviewed by clinicians using the SCID and found evidence of elevated PTSD symptoms among Hispanic male Vietnam veterans only when PTSD was assessed via self-report.

Two articles found significant interactions between PTSD severity and sociodemographic variables (e.g., ethnicity, gender) or trauma type (e.g., physical abuse vs. sexual abuse in childhood). For example, Mexican females exhibited more severe PTSD symptoms and scored higher on intrusion and avoidance symptom clusters as well as a cluster of remorse symptoms than a non-Latino White combined male and female sample (Norris, Perilla, Ibañez, et al., 2001).Balsam et al. (2010) also noted a significant Latino-ethnicity-by-typeof-childhood-abuse interaction on PTSD symptom severity. In particular, during instances when physical abuse was high, lesbian, gay, or bisexual Latino adults exhibited more severe PTSD symptoms than their non-Latino White counterparts.

\section{Within-Latino Group Differences in Conditional PTSD}

Two of the 28 articles specifically examined within-group differences in conditional risk for PTSD among Latino women (Heilemann et al., 2005; Rodriguez et al., 2008). Results were mixed. One article found higher PTSD severity as a function of generation in the U.S. among a community sample of Mexican women (Heilemann et al., 2005), whereas the other article did not find significant differences in PTSD prevalence between English-speaking and Spanish-speaking Latino women exposed to intimate partner violence (Rodriguez et al., 2008). No articles examined within-group differences in conditional PTSD among Latino men.

We note that three of the 26 articles that examined between-group differences did in fact report differences across Latino subgroups in PTSD onset and PTSD severity (Galea et al., 2004; Lewis-Fernández et al., 2008; Ortega \& Rosenheck, 2000). Galea et al (2004) reported that Dominicans and Puerto Ricans, but not "Other" Latinos, had elevated rates of PTSD onset compared to the combined non-Latino group. Research with specific Latino subgroups in the NVVRS found that Puerto Rican Vietnam veterans have more severe PTSD symptoms than non-Latino White veterans based on total symptom counts as measured by the Mississippi PTSD Scale and differential endorsement of PTSD symptom clusters (Ortega \& Rosenheck, 2000). It is notable that the same article found that "Other Hispanics" have less severe PTSD than non-Latino White veterans, although this effect may have been driven by the small sample size of this Latino subgroup $(n=35)$. Finally, in another article using the male subsample of the NVVRS assessed with the SCID, Puerto Rican veterans showed a more profound pattern of self-reported symptom severity than Mexican Americans when self-reports were used; however, there was no evidence of higher PTSD symptom reporting in the subsample using clinician-administered diagnostic interviews (LewisFernández et al., 2008). 


\section{Sociocultural Explanations}

Twenty-four of the 28 articles explored whether observed differences in conditional risk for PTSD prevalence, onset, persistence, or severity between Latinos and non-Latinos were explained by racial/ethnic variation in the tendency to experience any of the seven a priori identified sociocultural factors (Table 3 ). Independent effects or group differences in social disadvantage $(n=20)$ were the most commonly examined sociocultural factor, followed by peritraumatic responses $(n=6)$, structure of PTSD $(n=6)$, expressive style $(n=4)$, acculturation $(n=4)$, posttrauma coping $(n=2)$, and cultural values of familism and fatalism $(n=1)$.

Social disadvantage-Twenty of the 24 articles examined whether indicators of social disadvantage (e.g., socioeconomic status) or of relative or absolute deprivation (e.g., lack of health insurance, racism) (Braveman \& Gruskin, 2003) accounted for variation in conditional risk for PTSD in models adjusting for the independent effect of Latino ethnicity. Seventeen of the 20 articles examined main effects only, and thus did not test whether social disadvantage acted as a moderator or mediator of conditional risk. Of these 17 articles:

1. seven found support for a significant independent effect of social disadvantage (i.e., education, income, poverty index, work problems) on conditional risk above and beyond the effect of Latino ethnicity (Adams \& Boscarino, 2006; Balsam et al., 2010; DiGrande et al., 2008;

2. Galea et al., 2008; Galea et al., 2004; Norris, Perilla, Ibañez, et al., 2001; Rodriguez et al., 2008);

3. five did not find significant differences (Bowler et al., 2010; Heilemann et al., 2005; Stampfel et al., 2010; A. E. Williams et al., 2008; Zatzick et al., 2007);

4. and five adjusted for social disadvantage factors but did not test or report their effect on conditional risk (Adams \& Boscarino, 2005; Lewis-Fernández et al., 2008; Norris, Perilla, \& Murphy, 2001; Ortega \& Rosenheck, 2000; Schlenger et al., 1992).

We note here that only 14 of the 20 articles on social disadvantage reported information on the distribution of education either in the total sample or by racial/ethnic group. These articles show that on average $57.3 \%$ of participants reported having less than a high school diploma/GED, and $42.9 \%$ reported having at least some college education. Three out of the 14 articles documented variation in the distribution of education by racial/ethnic group; in these studies, non-Latino Whites relative to Latinos reported more mean years of education (12.9 years vs. 6.25 years, respectively) or endorsed having a college degree more frequently ( $57.9 \%$ vs. $20.6 \%$ ). However, only 8 of the 14 articles tested whether education had a main effect on PTSD probability, with three finding support for a negative association between education and conditional risk for PTSD (DiGrande et al., 2008; Norris, Perilla, Ibañez, et al., 2001; Balsam et al., 2010), and five finding a null main effect for education (Heilemann et al., 2005; Stampfel et al., 21010; Perilla et al., 2002; Galea et al., 2008; Adams \& Boscarino et al., 2006).

Three articles out of the 20 that examined indicators of social disadvantage explicitly tested whether these indicators accounted for differences in conditional risk for PTSD between Latinos and non-Latino Whites or Blacks using either adjusted logistic or linear regression models or mediation analyses (Dohrenwend et al., 2008; Perilla et al., 2002; Pole et al., 2005). Of these, two documented significant findings. Lower pre-war educational attainment accounted for higher PTSD onset in a SCID-diagnosed subsample of Latino male Vietnam veterans relative to non-Latino Blacks and non-Latino Whites (Dohrenwend et al., 2008). In addition, perceived discrimination was found to significantly explain the differential in 
PTSD severity between Latino and non-Latino White urban police officers, above and beyond peri-traumatic dissociation, social desirability, and coping (Pole et al., 2005). In contrast, in the only article to test a mediation model,Perilla et al. (2002) did not find a significant mediation effect for education on Latino ethnicity and PTSD onset.

Peritraumatic response-Six of the 24 articles examined whether differences in peritraumatic response across racial/ethnic groups explained the higher conditional risk among Latinos (Denson et al., 2007; Galea et al., 2002; Galea et al., 2008; Galea et al., 2004; Pole et al., 2005; Pole et al., 2001). Peritraumatic response refers to reactions that occur during or immediately after the traumatic event (e.g., peritraumatic dissociation, perievent panic symptoms), which can be influenced by sociocultural factors, such as idioms of distress (Lewis-Fernández et al., 2010). Consistently across the six studies, peri-traumatic responses were significant correlates of PTSD conditional risk above and beyond the main effect of Latino ethnicity. Two studies examined specific racial/ethnic group differences in peritraumatic responses.Galea et al. (2004) reported that Dominicans (and not other Latino subgroups) who endorsed peri-event panic following the WTC attack had markedly increased odds of PTSD onset relative to non-Latino Whites. Similarly, among a sample of urban police officers, greater peritraumatic dissociation accounted for $21 \%$ of the variance in PTSD symptom severity between Latinos and non-Latino Blacks, and $20 \%$ of the variance between Latinos and non-Latino Whites (Pole et al., 2005). The remaining four studies documented a significant main effect of peritraumatic dissociation (e.g., depersonalization, derealization) or peri-event panic symptoms on conditional risk for PTSD in ethnicityadjusted models (Denson et al., 2007; Galea et al., 2002; Galea et al., 2008; Pole et al., 2001).

Structure of PTSD—Six articles examined whether between-group variation in endorsement of PTSD symptom clusters or specific PTSD symptoms contributed to differential PTSD risk profiles (Marshall et al., 2009; Norris, Perilla, Ibañez, et al., 2001; Norris, Perilla, \& Murphy, 2001; Ortega \& Rosenheck, 2000; Perilla et al., 2002; Pole et al., 2005). All six of these articles reported significant differences. For example, re-experiencing and avoidance symptoms were more common among Latinos than non-Latino Whites and Blacks across a range of trauma-exposed samples (Marshall et al., 2009; Norris, Perilla, Ibañez, et al., 2001; Norris, Perilla, \& Murphy, 2001; Ortega \& Rosenheck, 2000; Perilla et al., 2002; Pole et al., 2005). In particular, Marshall and colleagues (2009) found that Latino survivors of physical injury reported more hyper-vigilance, flashbacks, and intrusive thoughts than non-Latino Whites, and greater avoidance of thoughts than non-Latino Blacks. Endorsement of specific symptom clusters may also co-vary by Latino ethnic subgroup, language, and gender. For example, Ortega and Rosenheck (2000) found that Puerto Rican veterans more frequently endorsed re-experiencing, hyper-arousal, guilt, and avoidance compared to non-Latino White veterans, whereas Mexican Americans more frequently endorsed hyper-arousal than non-Latino Whites. Re-experiencing and avoidance symptoms were higher among Spanish-speaking Latinos than English-Speaking Latinos (Perilla et al., 2002). Finally, Mexican women living in Mexico had higher intrusion and avoidance symptoms than non-Latino Whites (Norris, Perilla, Ibanez, \& Murphy, 2001).

Expressive style-Four of the 24 articles on sociocultural factors tested for evidence of the expressive style hypotheses by examining between-group differences in functional impairment and the extent to which social desirability accounts for variation in symptom endorsement patterns (Lewis-Fernández et al., 2008; Ortega \& Rosenheck, 2000; Pole et al., 2005; Pole et al., 2001). The expressive style hypothesis stems from NVVRS data showing that Puerto Rican (and to a lesser extent Mexican American) male veterans endorsed more PTSD symptoms than non-Latino White veterans after adjusting for pre-military and 
military factors, but without showing the higher functional impairment that would be expected with higher symptoms (Ortega \& Rosenheck, 2000). This was considered evidence of symptom over-reporting. Recent research, however, contradicts these initial findings.Pole et al. (2005) found evidence for a pattern of distress underreporting rather than an overreporting bias. In this sample, social desirability had a significant inverse relationship with PTSD severity (Pole et al., 2001), and also explained between-group variation in PTSD severity (Pole et al., 2005). Moreover, when Lewis-Fernández and colleagues (2008) examined functional impairment and PTSD severity using the NVVRS subsample interviewed by clinicians using the SCID, no evidence of heightened expressive style was found among Latino male Vietnam veterans for four out of five indicators of impairment (Global Assessment of Functioning, postwar unemployment, college education, and socioeconomic status). Thus, it appears that cultural patterns of expressive style may contribute only a partial explanation for variation in conditional risk between Latinos and non-Latino Whites and Blacks, especially when diagnostic inferences are made by clinicians rather than self-report measures.

Acculturation-Four articles included acculturation-related measures (e.g., nativity) in analyses of conditional risk for PTSD, comparing Spanish-speaking or immigrant Latinos with their English-speaking or US-born counterparts (Adams \& Boscarino, 2005; Ortega \& Rosenheck, 2000; Perilla et al., 2002; A. E. Williams et al., 2008). Three of the four articles that examined PTSD onset found mixed results.Williams et al. (2008) reported increased odds of PTSD onset among US-born relative to foreign-born participants following musculoskeletal injuries.Perilla et al. (2002), however, reported a different pattern: in cases where personal trauma and neighborhood trauma exposure were high following Hurricane Andrew, Spanish-speaking Latinos showed the highest rates of PTSD, followed by African Americans and non-Latino Whites; English-speaking Latinos were excluded from these analyses because of their small sample size. A third article did not find a statistically significant effect of acculturation (measured as language of survey administration, country of origin, or language preference as child/adult) on PTSD symptoms (Ortega \& Rosenheck, 2000). The last article adjusted for immigration status but did not report on the independent effect of this variable on PTSD prevalence (Adams \& Boscarino, 2005).

Fatalism, Familism, and Coping-Perilla et al. (2002) examined whether racial/ethnic variation in adherence to the cultural values of fatalism and familism, commonly found among Latinos (Lara, Gamboa, Kahramanian, Morales, \& Bautista, 2005), function as potential mediators in the relationship between Latino ethnicity and PTSD due to their influence on posttrauma coping strategies. They measured fatalism as the extent to which respondents endorsed coping strategies based on an external versus an internal locus of control. Familism was measured as the extent to which respondents positively endorsed the view that aging parents should live at home and that children should live at home until marriage. The authors found that fatalism mediated the onset of PTSD by modifying the relationship between avoidance and language among Latinos (Spanish-speaking vs. Englishspeaking Latinos). Familism, by contrast, was not a significant mediator. The mediational role of fatalism may be due to the postulated relationship between this cultural value and the use of passive rather than active coping strategies (Neff \& Hoppe, 1993), which may lead to higher vulnerability to PTSD. This hypothesis is supported by two other studies that also examined the relationship between posttrauma coping and PTSD severity (Denson et al., 2007; Pole et al., 2005). Latino police officers were found to use self-blaming and wishfulthinking coping strategies more often than White officers; use of these coping strategies explained a significant $12 \%$ of the variance in PTSD severity (Pole et al., 2005). Similarly, self-blame was associated with PTSD severity in models adjusting for ethnicity effects among a sample of men exposed to community violence (Denson et al., 2007). 


\section{Discussion}

Our systematic review of the literature on racial/ethnic differences in conditional risk for PTSD among Latinos found 28 articles that accounted for the effect of trauma exposure and also examined Latino and non-Latino (Whites, Blacks, or Combined) between-group differences and within-Latino group differences in conditional risk for PTSD prevalence (including onset and persistence) and PTSD severity. We also assessed the extent to which included articles examined between-group and Latino subgroup variation in PTSD probability as a function of seven sociocultural factors identified in the literature that might explain the relationship between Latino ethnicity and PTSD. We summarize key findings below and offer directions for future research.

Our first aim was to describe study characteristics of the selected sample of articles. We found several common limitations across studies. Twenty-three of the 28 articles (82.1\%) assessed single traumas; most only included male samples (median percentage female $=$ 41.05). Twenty-five articles (89.3\%) used lay-administered structured diagnostic interviews or self-report symptom checklists to derive estimations of PTSD risk and infer a probable PTSD diagnosis. Only three articles (10.7\%) used clinician-administered diagnostic interviews. The quality and scope of the adjustments made for trauma exposure were also not uniform. Many articles used only objective measures of direct exposure (e.g., distance from epicenter of disaster) without including subjective measures of trauma exposure, severity, and subsequent distress. Yet, participants' subjective perceptions of the severity of their traumas provide additional information beyond that obtained from objective indicators (Fikretoglu et al., 2006), which may help explain the findings of differential conditional risk. In addition, these objective indicators of trauma exposure seldom accounted for other lifetime traumatic events or childhood maltreatment (exceptions include Adams \& Boscarino, 2006; Denson et al., 2007; Fontana \& Rosenheck, 1994; Galea et al., 2008; Ortega \& Rosenheck, 2000; Roberts et al., 2010). Even when such assessments were conducted, the methods used for adjustment may not have fully captured the impact of accumulated vulnerability, or a life at "risk of risks" stemming from social characteristics that configure vulnerability among subgroups or subpopulations (Frohlich \& Potvin, 2008). To this end, the lived experience of a life at risk of risks and of social vulnerability may not be well captured in models that adjust for trauma exposure with dichotomous or ordinal measures. Similarly, individual-level assessments of socioeconomic position may not adequately capture lifetime exposure to social vulnerability (D. R. Williams, Mohammed, Leavell, \& Collins, 2010). It is possible that individuals at risk of risks have different thresholds for experiencing psychological sequelae associated with trauma and that extant measures of social vulnerability do not adequately measure exposure to repeated social disadvantage. We recommend that future research more closely address differential pathways to PTSD by accounting for incident and lifetime exposure to trauma using a combination of objective and subjective measures. Furthermore, empirical research on the association between socioeconomic position and conditional risk for PTSD should explicitly describe the sociodemographic characteristics of the sample (e.g., education, income) and where possible test for interactions between indicators of socioeconomic position and race/ ethnicity to determine differential patterning of socioeconomic risk and protective factors by race/ethnicity.

Our second aim was to evaluate methodological quality through the use of risk-of-bias assessments. We assessed the extent to which each study exhibited low risk, high risk, or unclear risk of selection bias, attrition bias, and reporting bias using the Cochrane Risk of Bias assessment tool as discussed in the Cochrane Handbook for Systematic Reviews of Interventions (Higgins \& Green, 2011). Sixteen articles (57\%) drew from non-random samples exhibiting high selection bias. Although each article exhibited low risk of reporting 
bias, 17 articles (61\%)exhibited high risk of attribution bias, or unclear risk of attrition bias due to incomplete reporting. Seven articles (25\%) focusing on PTSD prevalence or persistence exhibited low risk across the three bias domains, which represent the highest quality articles. Future research should use random sampling to arrive at representative samples and adequately address missing data (for examples see Dohrenwend et al., 2008; Galea et al., 2008; Galea et al., 2004; Lewis-Fernández et al., 2008; Ortega \& Rosenheck, 2000; Roberts et al., 2010; Schlenger et al., 1992).

Most studies on differential racial/ethnic PTSD risk were conducted with predominantly male samples, or in male-dominated work contexts, such as the military or police work, and very few examined gender differences in between-group variation in conditional risk for PTSD (exceptions include Heilemann et al., 2005; Rodriguez et al., 2008; Norris et al., 2001). This is surprising, given the extensive body of research demonstrating gender differences in trauma exposure, PTSD prevalence, and peritraumatic responses (Galea et al., 2008; Montoya, Covarrubias, Patek, \& Graves, 2003; Olff, Langeland, Draijer, \& Gersons, 2007; Tolin \& Foa, 2006); (Guarnaccia et al., 2010; Lewis-Fernández et al., 2010). Future research should more closely examine gender and, in particular, the intersection between gender, race, ethnicity, culture, nativity, and socioeconomic position on differential risk and mediators of PTSD among Latino communities.

Our third aim was to examine whether there were consistent between-group or within-Latino group differences in conditional PTSD outcomes after adjustment for trauma exposure. Twenty-one articles (75.0\%) reported significant Latino vs. non-Latino between-group differences; consistent effects were found for Latino and non-Latino White differences in PTSD severity ( $n=11$ of 12 articles, $92 \%$ ) and PTSD onset ( $n=6$ of $8,75 \%)$, whereas the evidence was more mixed concerning racial/ethnic differences in PTSD prevalence ( $n=6$ of $11,55 \%)$ and PTSD persistence ( $n=2$ of 5, 40\%). We note that articles on PTSD persistence typically did not track PTSD persistence at the individual level, and instead, presented aggregate PTSD rates for the full sample at each time point, obscuring the exact relationship between new-onset and persistence of PTSD for each respondent.

In regard to within-Latino group differences in PTSD, the evidence was inconclusive. Some results suggest that specific Latino subgroups (e.g., Mexican women or Puerto Ricans and Dominicans of both genders) may be particularly at risk for elevated PTSD prevalence and onset. Nativity and language may also have differential associations to PTSD conditional risk among Latinos, but the direction of the effect is unclear. Future research should examine the effect of Latino subgroup differences (e.g., nativity, language, sub-ethnicity) and interactions with sociocultural factors on conditional risk for PTSD.

Our review suggests that variation in conditional risk for PTSD is not statistically significant when clinician-administered diagnostic interviews are used in lieu of self-reports. Clinicianadministered semi-structured diagnostic interviews may inadvertently adjust for respondents' perceptions of trauma severity and their local understandings of associated psychological effects because the clinician-rater ultimately determines the presence of PTSD symptoms and ratings of symptom severity. In doing so, clinician-administered diagnostic interviews may be less likely than self-report measures to capture the lived psychological and social realities of individuals exposed to trauma by systematically attenuating individual-level reactions. On the other hand, studies that rely strictly on self-report measures and symptom cutoff scores to infer a probable PTSD diagnosis may also be problematic given the preliminary evidence of cross-cultural variation in PTSD symptom constellations. In fact, lay-administered diagnostic instruments are less desirable than clinician-administered semi-structured diagnostic interviews in light of the low concordance between these two methods when applied to PTSD among Latinos (Alegria et al., 2009; 
Lewis-Fernández et al., 2008). The differential findings on conditional risk for PTSD among Latinos as a function of measurement tool (clinician or lay administered diagnostic interviews, self-report measures) preclude drawing firm conclusions about the accuracy and validity of one measurement tool over another. We recommend that future research use multi-method assessments of PTSD symptoms (including both objective and subjective measures of trauma and severity) and PTSD diagnoses, and encourage evaluations of PTSD that combine diagnostic interviews with assessments of functional impairment, in order to ascertain the impairment criterion for the diagnosis (Lewis-Fernández et al., 2008). Future research on racial/ethnic differences in conditional risk for PTSD might also benefit from the incorporation of physiological markers of PTSD (e.g., physiological reactivity to trauma cues) to confirm or disconfirm PTSD diagnoses derived from self-report scales or clinicianadministered interviews, thereby helping to disentangle variation in PTSD estimates due to measurement error.

Our fourth aim was to identify and describe the sociocultural factors that may contribute to differences in conditional risk for PTSD. Twenty-four studies explored whether sociocultural factors could account for observed differences in conditional risk related to PTSD prevalence, onset, persistence, or severity. Consistent support was found for four of the seven sociocultural explanations tested, including differences in expressive style, structure of PTSD, peri-traumatic responses, and social disadvantage. Support was also documented for the direct effect of coping (self-blame) and fatalism on probable PTSD, but less consistently, as only explored in two articles. Mixed support was found for the effect of acculturation in explaining conditional risk differences.

The most commonly tested sociocultural explanations included differences in peritraumatic response, structure of PTSD, and indicators of social disadvantage. To this end, the strongest support was observed for differences in peri-traumatic responses, including peritraumatic dissociation and peri-event panic. Latinos relative to non-Latino Whites exhibited a higher propensity to experience peri-traumatic responses, disproportionately endorsed symptoms of re-experiencing and avoidance, and occupied positions of low socioeconomic status.

The elevated rates of peritraumatic dissociation and peri-event panic among Latinos may be linked to the cultural predisposition to experience cultural syndromes such as ataques de nervios in response to acute stress (Lewis-Fernández, Garrido-Castillo, et al., 2002; Ruef et al., 2000). Ataque de nervios is a cultural syndrome that often involves typical and atypical panic and dissociation symptoms (American Psychiatric Association, 2000). Prevalence of ataques is associated with prevalence of panic disorder, PTSD, depressive disorders, anxiety sensitivity, childhood trauma, dissociative symptoms, dissociative predisposition, and noncriterion PTSD symptoms (Cintrón, Carter, \& Sbrocco, 2005; Guarnaccia et al., 2010; Guarnaccia, Rivera, Franco, \& Neighbors, 1996; Hinton, Chong, Pollack, Barlow, \& McNally, 2008; Lewis-Fernández et al., 2010; Lewis-Fernández, Guarnaccia, et al., 2002; Norris, Weisshaar, et al., 2001; Schechter et al., 2000). These associations make it plausible that once exposed to a traumatic event Latinos may experience a peritraumatic or peri-event emotional response in the form of an ataque de nervios, and this in turn may lead to increased odds of PTSD onset or persistence.

In addition, a small number of studies also found interactions between ethnicity and gender, suggesting a need for further research on the variation of cultural and psychosocial characteristics by Latino subgroup, gender, and their relative influence on PTSD risk. Future research should more closely examine Latino and non-Latino between-group and withinLatino group variation in relative salience of PTSD symptom clusters, co-occurrence with peritraumatic responses, and interplay with cultural syndromes (Hinton \& Lewis-Fernandez, 2011). To this end, incorporation in mental health research of subsections from the Outline 
for Cultural Formulation and/or the Cultural Formulation Interview in DSM-5 (LewisFernández, 2009) may help researchers generate hypotheses about how gender, language, and culture interact to contribute to racial/ethnic variation in conditional risk for PTSD. For example, the Cultural Formulation Interview can be used as a tool to systematically gather information about key sociocultural domains that might impact clinical presentation such as the cultural definitions of the individual's illness and cultural perceptions of cause, context, and support.

\section{Limitations}

Our systematic review has several limitations. First, the heterogeneity in analytic method, article quality, and outcome measures prevented us from conducting a meta-analysis. Second, as with any systematic review, we may have missed articles that met our inclusion criteria. However, we used multiple databases, multiple coders, and manual searches to mitigate this limitation. Third, we did not distinguish between articles that adjusted for cooccurring psychiatric conditions or physical health conditions and those that did not. Future research should explore the relative influence of co-occurring psychiatric conditions and physical health conditions on PTSD risk and on sociocultural explanations. Last, our measure of methodological quality or risk of bias did not capture the variance in analytic methods across studies, and relied on subjective assessment of risk domains. However, we used multiple coders and a well-validated evaluation tool to assess risk of bias to mitigate this limitation.

\section{Conclusion}

Our findings suggest that Latinos relative to non-Latino Whites (and occasionally to nonLatino Blacks) exhibit higher conditional risk for PTSD after accounting for trauma exposure particularly with respect to elevated rates of PTSD onset and severity. The evidence is more mixed with respect to PTSD prevalence and persistence. We note that higher conditional risk for PTSD among Latinos is not observed when clinicianadministered diagnostic interviews as opposed to lay-administered structured interviews or self-report scales are used to measure PTSD. Nonetheless, the elevated rates of probable PTSD onset and PTSD severity are particularly concerning when one considers that Latinos are also less likely to receive treatment once they meet diagnostic threshold for PTSD (Roberts et al., 2010). In tandem, these findings imply that PTSD poses an acute public health problem for Latinos. More research is needed to understand the potential mechanisms underlying these differences and how measurement variance contributes to observed racial/ ethnic differences in conditional risk for PTSD. Our results suggest that sociocultural differences in the experience of peri-traumatic responses and in differential endorsement of PTSD symptom clusters may partly explain the racial/ethnic variation in conditional risk. Future research should continue to systematically examine differences in conditional risk for PTSD between Latinos and non-Latinos using theoretically-driven models that formally test for interaction effects between sociocultural factors, ethnicity, and PTSD probability, and at a minimum include appropriate adjustments for indicators of social disadvantage.

\section{Acknowledgments}

This systematic review was supported by multiple funding sources. C. Alcántara was supported by a grant through the W.K. Kellogg Foundation (Kellogg Health Scholars Program) while at Harvard School of Public Health. M.Casement was supported by the National Institute of Mental Health Institutional Training Grant T32-MH019836, awarded to Terence M. Keane at the National Center for PTSD, Boston, MA. R.Lewis-Fernández was supported by institutional funds from New York State Psychiatric Institute, Columbia University, R01 MH077226 (LewisFernández), and R01 MH072833 (Neria). The funding agencies did not play a role in study design, collection, analysis, interpretation of data, writing of the report, or journal submission. The content of this manuscript is solely the responsibility of the authors and does not necessarily represent the official views of the W.K. Kellogg 
Foundation, the New York State Psychiatric Institute, the National Institute of Mental Health, or the National Institutes of Health.

\section{References}

Adams RE, Boscarino JA. Differences in mental health outcomes among Whites, African Americans, and Hispanics following a community disaster. Psychiatry: Interpersonal and Biological Processes. 2005; 68(3):250-265.

Adams RE, Boscarino JA. Predictors of PTSD and delayed PTSD after disaster: the impact of exposure and psychosocial resources. J Nerv Ment Dis. 2006; 194(7):485-493. [PubMed: 16840844]

Alegría M, Canino G, Shrout PE, Woo M, Duan N, Vila D, Meng X-L. Prevalence of mental illness in immigrant and non-immigrant U.S. Latino groups. The American Journal of Psychiatry. 2008; 165(3):359-369. [PubMed: 18245178]

Alegria M, Shrout PE, Torres M, Lewis-Fernández R, Abelson JM, Powell M, Canino G. Lessons learned from the clinical reappraisal study of the Composite International Diagnostic Interview with Latinos. International Journal of Methods in Psychiatric Research. 2009; 18(2):84-95. [PubMed: 19507168]

Alonso J, Petukhova M, Vilagut G, Chatterji S, Heeringa S, Ustun TB, Kessler RC. Days out of role due to common physical and mental conditions: results from the WHO World Mental Health surveys. Mol Psychiatry. 2011; 16(12):1234-1246. [PubMed: 20938433]

American Psychiatric Association. Diagnostic and statistical manual of mental disorders : DSM-IVTR. Washington, DC: American Psychiatric Association; 2000. (4th, text revision 2000 ed.)

Asnaani A, Richey JA, Dimaite R, Hinton DE, Hofmann SG. A cross-ethnic comparison of lifetime prevalence rates of anxiety disorders. Journal of Nervous and Mental Disease. 2010; 198(8):551555. [PubMed: 20699719]

Balsam KF, Lehavot K, Beadnell B, Circo E. Childhood abuse and mental health indicators among ethnically diverse lesbian, gay, and bisexual adults. J Consult Clin Psychol. 2010; 78(4):459-468. [PubMed: 20658803]

Bowler RM, Han H, Gocheva V, Nakagawa S, Alper H, Digrande L, Cone JE. Gender differences in probable posttraumatic stress disorder among police responders to the 2001 World Trade Center terrorist attack. Am J Ind Med. 2010

Braveman P, Gruskin S. Defining equity in health. J Epidemiol Community Health. 2003; 57(4):254258. [PubMed: 12646539]

Breslau N, Kessler RC, Chilcoat HD, Schultz LR, Davis GC, Andreski P. Trauma and posttraumatic stress disorder in the community: The 1996 Detroit Area Survey of Trauma. Archives of General Psychiatry. 1998; 55(7):626-632. [PubMed: 9672053]

Cintrón JA, Carter MM, Sbrocco T. Ataques de nervios in relation to anxiety sensitivity among island Puerto Ricans. Culture, Medicine and Psychiatry. 2005; 29(4):415-431.

Denson TF, Marshall GN, Schell TL, Jaycox LH. Predictors of posttraumatic distress 1 year after exposure to community violence: The importance of acute symptom severity. Journal of Consulting and Clinical Psychology. 2007; 75(5):683-692. [PubMed: 17907850]

DiGrande L, Perrin MA, Thorpe LE, Thalji L, Murphy J, Wu D, Brackbill RM. Posttraumatic stress symptoms, PTSD, and risk factors among lower Manhattan residents 2-3 years after the September 11, 2001 terrorist attacks. Journal of Traumatic Stress. 2008; 21(3):264-273. [PubMed: 18553414]

Dohrenwend BP, Turner JB, Turse NA, Lewis-Fernández R, Yager TJ. War-related posttraumatic stress disorder in Black, Hispanic, and Majority White Vietnam veterans: The roles of exposure and vulnerability. Journal of Traumatic Stress. 2008; 21(2):133-141. [PubMed: 18404630]

Fikretoglu D, Brunet A, Best S, Metzler T, Delucchi K, Weiss DS, Marmar C. The Relationship Between Peritraumatic Distress and Peritraumatic Dissociation: An Examination of Two Competing Models. Journal of Nervous and Mental Disease. 2006; 194(11):853-858. [PubMed: 17102710] 
Fontana A, Rosenheck R. Posttraumatic stress disorder among Vietnam theater veterans: A causal model of etiology in a community sample. Journal of Nervous and Mental Disease. 1994; 182(12): 677-684. [PubMed: 7989911]

Frohlich KL, Potvin L. Transcending the known in public health practice: The inequality paradox: The population approach and vulnerable populations. American Journal of Public Health. 2008; 98(2): 216-221. [PubMed: 18172133]

Galea S, Ahern J, Resnick H, Kilpatrick D, Bucuvalas M, Gold J, Vlahov D. Psychological sequelae of the September 11 terrorist attacks in New York City. The New England Journal of Medicine. 2002; 346(13):982-987. [PubMed: 11919308]

Galea S, Ahern J, Tracy M, Hubbard A, Cerda M, Goldmann E, Vlahov D. Longitudinal determinants of posttraumatic stress in a population-based cohort study. Epidemiology. 2008; 19(1):47-54. [PubMed: 18091003]

Galea S, Vlahov D, Tracy M, Hoover DR, Resnick H, Kilpatrick D. Hispanic ethnicity and posttraumatic stress disorder after a disaster: evidence from a general population survey after September 11, 2001. Ann Epidemiol. 2004; 14(8):520-531. [PubMed: 15350950]

Guarnaccia PJ, Lewis-Fernández R, Pincay IM, Shrout P, Guo J, Torres M, Alegria M. Ataque de nervios as a marker of social and psychiatric vulnerability: Results from the NLAAS. International Journal of Social Psychiatry. 2010; 56(3):298-309. [PubMed: 19592438]

Guarnaccia PJ, Rivera M, Franco F, Neighbors C. The experiences of ataques de nervios: Towards an anthropology of emotions in Puerto Rico. Culture, Medicine and Psychiatry. 1996; 20(3):343-367.

Heilemann MV, Kury FS, Lee KA. Trauma and posttraumatic stress disorder symptoms among low income women of Mexican descent in the United States. J Nerv Ment Dis. 2005; 193(10):665672. [PubMed: 16208162]

Higgins, J.; Green, S., editors. Cochrane Handbook for Systematic Reviews of Interventions Version 5.1.0 [updated March 2011]. The Cochrane Collaboration; 2011.

Hinton DE, Chong R, Pollack MH, Barlow DH, McNally RJ. Ataque de nervios: Relationship to anxiety sensitivity and dissociation predisposition. Depression and Anxiety. 2008; 25(6):489-495. [PubMed: 17570492]

Hinton DE, Lewis-Fernandez R. The cross-cultural validity of posttraumatic stress disorder: implications for DSM-5. Depress Anxiety. 2011; 28(9):783-801. [PubMed: 21910185]

Kessler RC, Sonnega A, Bromet E, Hughes M. Posttraumatic stress disorder in the National Comorbidity Survey. Archives of General Psychiatry. 1995; 52(12):1048-1060. [PubMed: 7492257]

Koopman C, Drescher K, Bowles S, Gusman F, Blake D, Dondershine H, Spiegel D. Acute dissociative reactions in veterans with PTSD. Journal of Trauma \& Dissociation. 2001; 2(1):91111.

Kulka, RA.; Schlenger, WE.; Fairbank, JA.; Hough, RL.; Jordan, BK.; Marmar, CR.; Weiss, DS. Trauma and the Vietnam war generation: Report of findings from the National Vietnam Veterans Readjustment Study. Philadelphia, PA US: Brunner/Mazel; 1990.

Lara M, Gamboa C, Kahramanian MI, Morales LS, Bautista DEH. Acculturation and Latino health in the United States: A review of the literature and its sociopolitical context. Annual Review of Public Health. 2005; 26:367-397.

Laria, AJ.; Lewis-Fernández, R. Latino Patients. In: Lim, RF., editor. Clinical manual of cultural psychiatry. Arlington, VA US: American Psychiatric Publishing, Inc; 2006. p. 119-173.

Lewis-Fernández R. The Cultural Formulation. Transcultural Psychiatry. 2009; 46:379-382. [PubMed: 19837777]

Lewis-Fernández R, Garrido-Castillo P, Bennasar MC, Parrilla EM, Laria AJ, Ma G, Petkova E. Dissociation, childhood trauma, and ataque de nervios among Puerto Rican psychiatric outpatients. The American Journal of Psychiatry. 2002; 159(9):1603-1605. [PubMed: 12202287]

Lewis-Fernández R, Gorritz M, Raggio GA, Pelaez C, Chen H, Guarnaccia PJ. Association of traumarelated disorders and dissociation with four idioms of distress among Latino psychiatric outpatients. Cult Med Psychiatry. 2010; 34(2):219-243. [PubMed: 20414799] 
Lewis-Fernández R, Guarnaccia PJ, Martínez IE, Salmán E, Schmidt A, Liebowitz M. Comparative phenomenology of ataques de nervios, panic attacks, and panic disorder. Culture, Medicine and Psychiatry. 2002; 26(2):199-223.

Lewis-Fernández R, Turner JB, Marshall R, Turse N, Neria Y, Dohrenwend BP. Elevated rates of current PTSD among Hispanic veterans in the NVVRS: True prevalence or methodological artifact? Journal of Traumatic Stress. 2008; 21(2):123-132. [PubMed: 18404629]

Liberati A, Altman DG, Tetzlaff J, Mulrow C, Gøtzsche PC, Ioannidis JPA, Moher D. The PRISMA Statement for Reporting Systematic Reviews and Meta- Analyses of Studies That Evaluate Health Care Interventions: Explanation and Elaboration. Annals of Internal Medicine. 2009; 151(4):W-65-W-94. [PubMed: 19622512]

Marshall GN, Schell TL, Miles JNV. Ethnic differences in posttraumatic distress: Hispanics' symptoms differ in kind and degree. Journal of Consulting and Clinical Psychology. 2009; 77(6): 1169-1178. [PubMed: 19968392]

Moher D, Liberati A, Tetzlaff J, Altman DG, The PG. Preferred Reporting Items for Systematic Reviews and Meta-Analyses: The PRISMA Statement. PLoS Med. 2009; 6(7):e1000097. [PubMed: 19621072]

Montoya ID, Covarrubias LD, Patek JA, Graves JA. Posttraumatic stress disorder among Hispanic and African-American drug users. The American Journal of Drug and Alcohol Abuse. 2003; 29(4): 729-741. [PubMed: 14713136]

Neff JA, Hoppe SK. Race/ethnicity, acculturation, and psychological distress: Fatalism and religiosity as cultural resources. Journal of Community Psychology. 1993; 21(1):3-20.

Nock MK, Hwang I, Sampson N, Kessler RC, Angermeyer M, Beautrais A, Williams DR. Crossnational analysis of the associations among mental disorders and suicidal behavior: findings from the WHO World Mental Health Surveys. PLoS Med. 2009; 6(8):e1000123. [PubMed: 19668361]

Norris FH, Perilla JL, Ibañez GE, Murphy AD. Sex differences in symptoms of posttraumatic stress: Does culture play a role? Journal of Traumatic Stress. 2001; 14(1):7-28.

Norris FH, Perilla JL, Murphy AD. Postdisaster stress in the United States and Mexico: A crosscultural test of the multicriterion conceptual model of posttraumatic stress disorder. Journal of Abnormal Psychology. 2001; 110(4):553-563. [PubMed: 11727945]

Norris FH, Weisshaar DL, Conrad ML, Diaz EM, Murphy AD, Ibanez GE. A qualitative analysis of posttraumatic stress among Mexican victims of disaster. Journal of Traumatic Stress. 2001; 14(4): 741-756. [PubMed: 11776421]

Olff M, Langeland W, Draijer N, Gersons BPR. Gender differences in posttraumatic stress disorder. Psychological Bulletin. 2007; 133(2):183-204. [PubMed: 17338596]

Ortega AN, Rosenheck R. Posttraumatic stress disorder among Hispanic Vietnam veterans. The American Journal of Psychiatry. 2000; 157(4):615-619. [PubMed: 10739422]

Perilla JL, Norris FH, Lavizzo EA. Ethnicity, culture, and disaster response: Identifying and explaining ethnic differences in PTSD six months after Hurricane Andrew. Journal of Social and Clinical Psychology. 2002; 21(1):20-45.

Pole N, Best SR, Metzler T, Marmar CR. Why Are Hispanics at Greater Risk for PTSD? Cultural Diversity and Ethnic Minority Psychology. 2005; 11(2):144-161. [PubMed: 15884985]

Pole N, Best SR, Weiss DS, Metzler T, Liberman AM, Fagan J, Marmar CR. Effects of gender and ethnicity on duty-related posttraumatic stress symptoms among urban police officers. Journal of Nervous and Mental Disease. 2001; 189(7):442-448. [PubMed: 11504321]

Pole N, Gone JP, Kulkarni M. Posttraumatic stress disorder among ethnoracial minorities in the United States. Clinical Psychology: Science and Practice. 2008; 15(1):35-61.

Roberts AL, Gilman SE, Breslau J, Breslau N, Koenen KC. Race/ethnic differences in exposure to traumatic events, development of post-traumatic stress disorder, and treatment-seeking for posttraumatic stress disorder in the United States. Psychol Med. 2010:1-13.

Rodriguez MA, Heilemann MV, Fielder E, Ang A, Nevarez F, Mangione CM. Intimate partner violence, depression, and PTSD among pregnant Latina women. Annals of Family Medicine. 2008; 6(1):44-52. [PubMed: 18195314] 
Ruef AM, Litz BT, Schlenger WE. Hispanic ethnicity and risk for combatrelated posttraumatic stress disorder. Cultural Diversity and Ethnic Minority Psychology. 2000; 6(3):235-251. [PubMed: 10938633]

Sabogal F, Marín G, Otero-Sabogal R, Marín BV. Hispanic familism and acculturation: What changes and what doesn't? Hispanic Journal of Behavioral Sciences. 1987; 9(4):397-412.

Sareen J, Cox BJ, Clara I, Asmundson GJ. The relationship between anxiety disorders and physical disorders in the U.S. National Comorbidity Survey. Depress Anxiety. 2005; 21(4):193-202. [PubMed: 16075453]

Schechter DS, Marshall R, Salmán E, Goetz D, Davies S, Liebowitz MR. Ataque de nervios and history of childhood trauma. Journal of Traumatic Stress. 2000; 13(3):529-534. [PubMed: 10948492]

Schlenger WE, Kulka RA, Fairbank JA, Hough RL. The prevalence of posttraumatic stress disorder in the Vietnam generation: A multimethod, multisource assessment of psychiatric disorder. Journal of Traumatic Stress. 1992; 5(3):333-363.

Schnurr PP, Lunney CA, Sengupta A. Risk Factors for the Development Versus Maintenance of Posttraumatic Stress Disorder. Journal of Traumatic Stress. 2004; 17(2):85-95. [PubMed: 15141781]

Stampfel CC, Chapman DA, Alvarez AE. Intimate partner violence and posttraumatic stress disorder among high-risk women: Does pregnancy matter? Violence Against Women. 2010; 16(4):426443. [PubMed: 20224113]

Stein DJ, Chiu WT, Hwang I, Kessler RC, Sampson N, Alonso J, Nock MK. Cross-national analysis of the associations between traumatic events and suicidal behavior: findings from the WHO World Mental Health Surveys. PLoS One. 2010; 5(5):e10574. [PubMed: 20485530]

Tolin DF, Foa EB. Sex differences in trauma and posttraumatic stress disorder: A quantitative review of 25 years of research. Psychological Bulletin. 2006; 132(6):959-992. [PubMed: 17073529]

Tsuang, MT.; Tohen, M.; Zahner, GEP. Textbook in psychiatric epidemiology. New York, NY US: Wiley-Liss; 1995.

Williams AE, Smith WR, Starr AJ, Webster DC, Martinez RJ, Vojir CP, Morgan SJ. Ethnic differences in posttraumatic stress disorder after musculoskeletal trauma. J Trauma. 2008; 65(5): 1054-1065. [PubMed: 19001973]

Williams DR, Mohammed SA, Leavell J, Collins C. Race, socioeconomic status, and health: complexities, ongoing challenges, and research opportunities. Ann N Y Acad Sci. 2010; 1186:69101. [PubMed: 20201869]

Zatzick DF, Rivara FP, Nathens AB, Jurkovich GJ, Wang J, Fan M-Y, MacKenzie EJ. A nationwide US study of post-traumatic stress after hospitalization for physical injury. Psychological Medicine: A Journal of Research in Psychiatry and the Allied Sciences. 2007; 37(10):1469-1480. 


\section{Research Highlights}

- We evaluate 28 articles on racial/ethnic differences in conditional risk for PTSD.

- Evidence of Latino and non-Latino White differences in PTSD severity and PTSD onset

- Mixed support for differences in conditional PTSD prevalence and persistence

- No differences in PTSD observed when clinicians administer diagnostic interviews.

- Support for racial/ethnic variation in peri-traumatic responses and PTSD structure. 


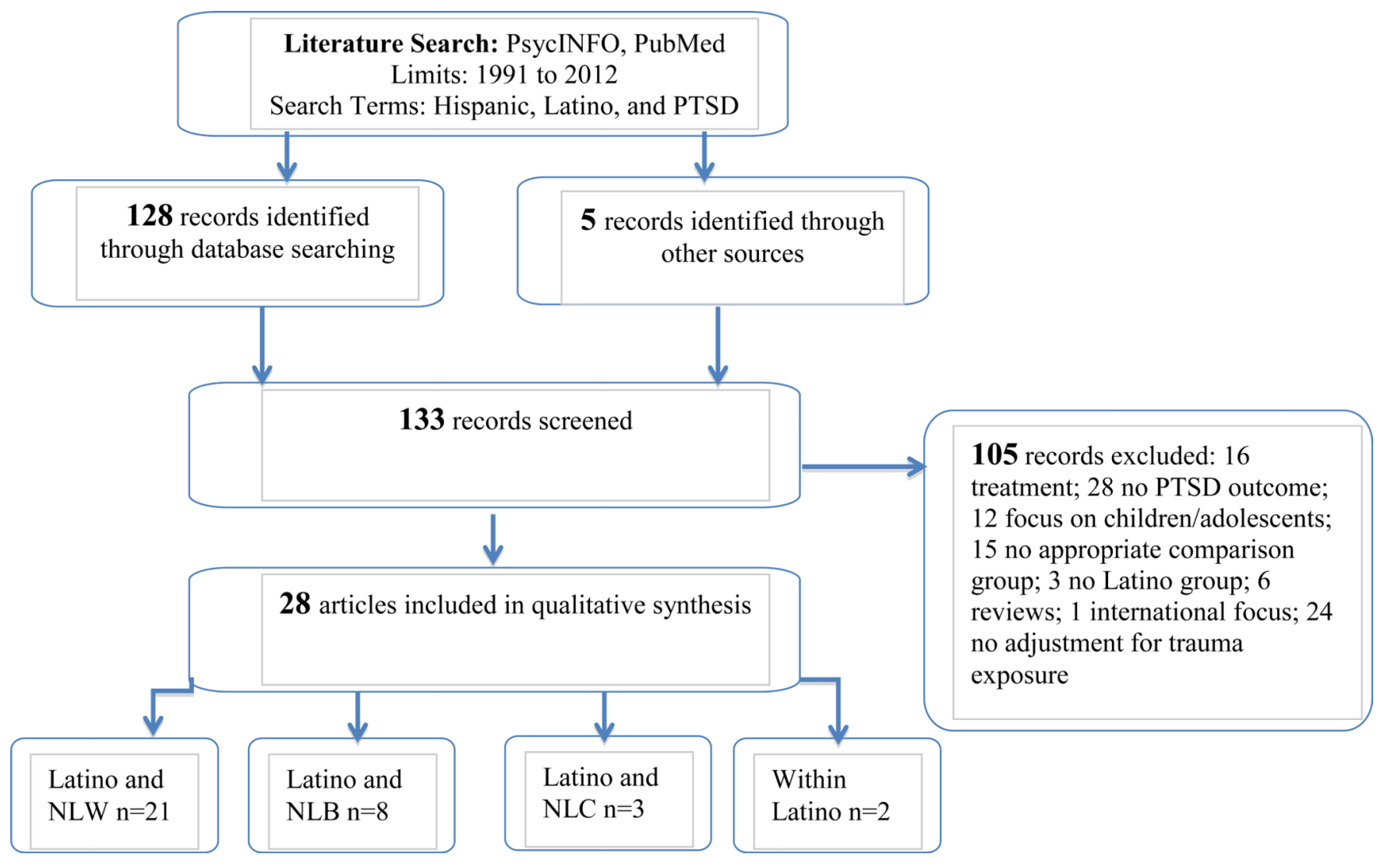

Figure 1. Flow Diagram of Article Selection

Note:

$\mathrm{NLW}=$ Non-Latino White $\mathrm{NLB}=$ Non-Latino Black; NLC $=$ Non-Latino Combined Between-group and within-group totals do not add up to 28 because articles included more than one comparison group. 


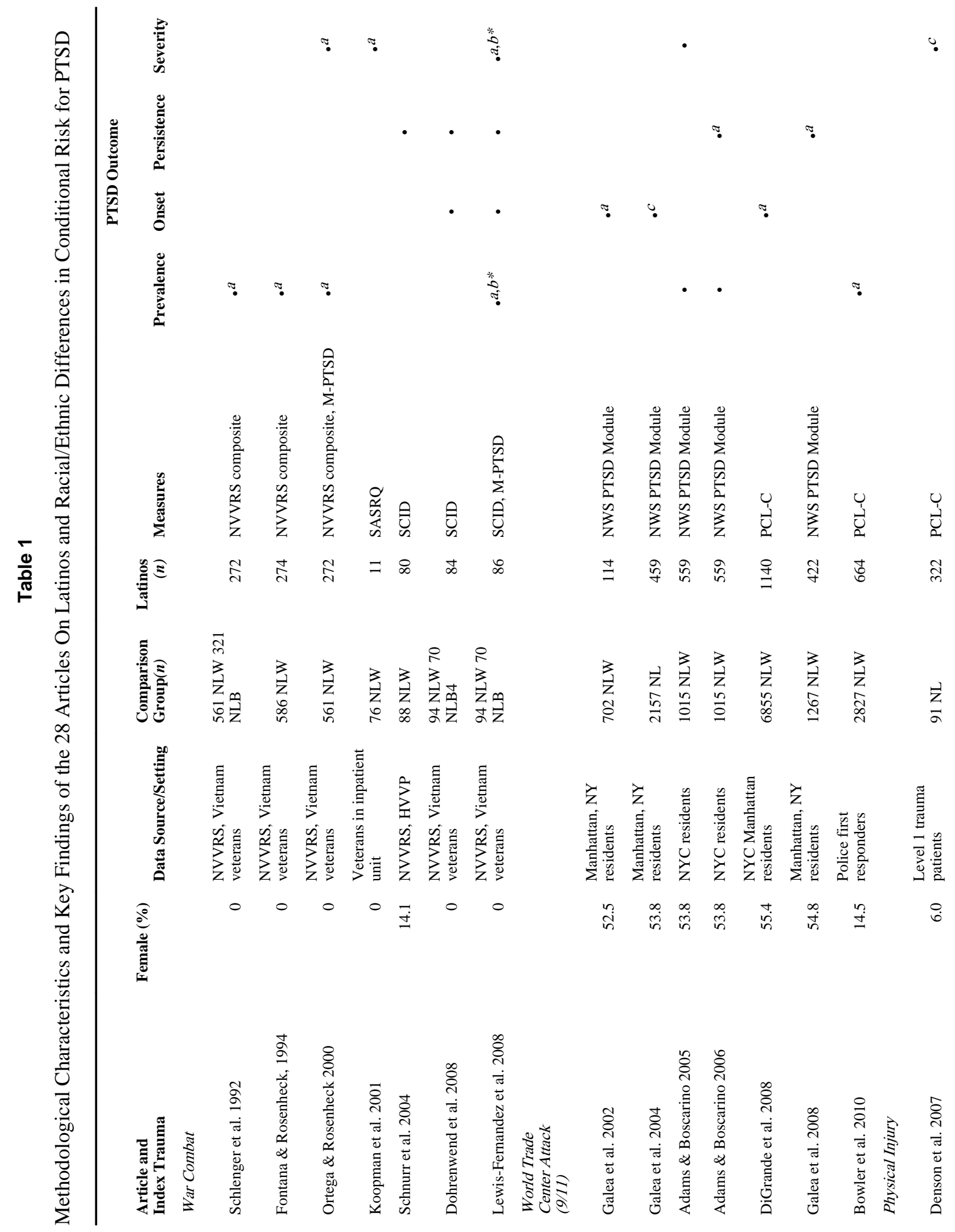




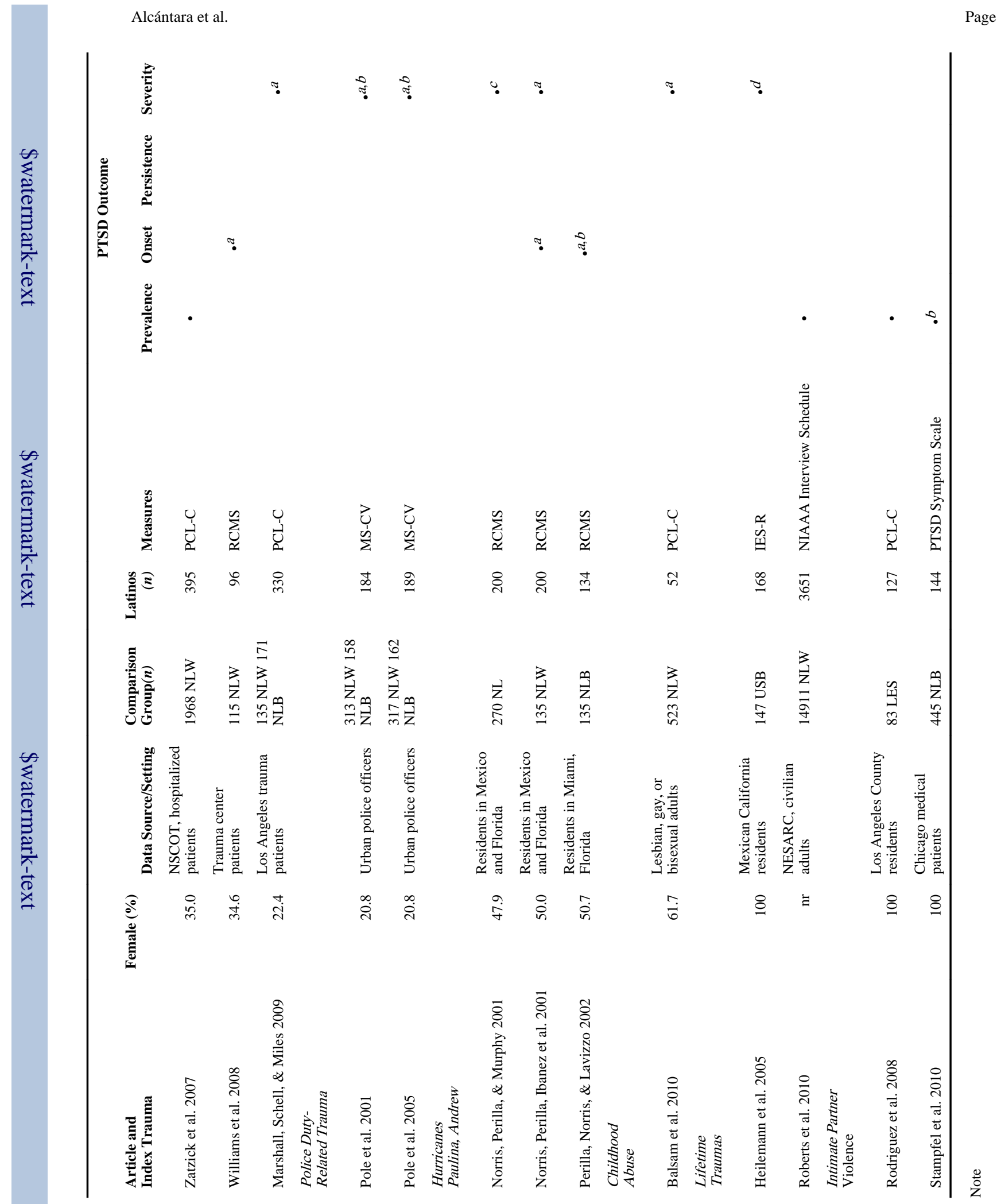

Clin Psychol Rev. Author manuscript; available in PMC 2014 February 01. 


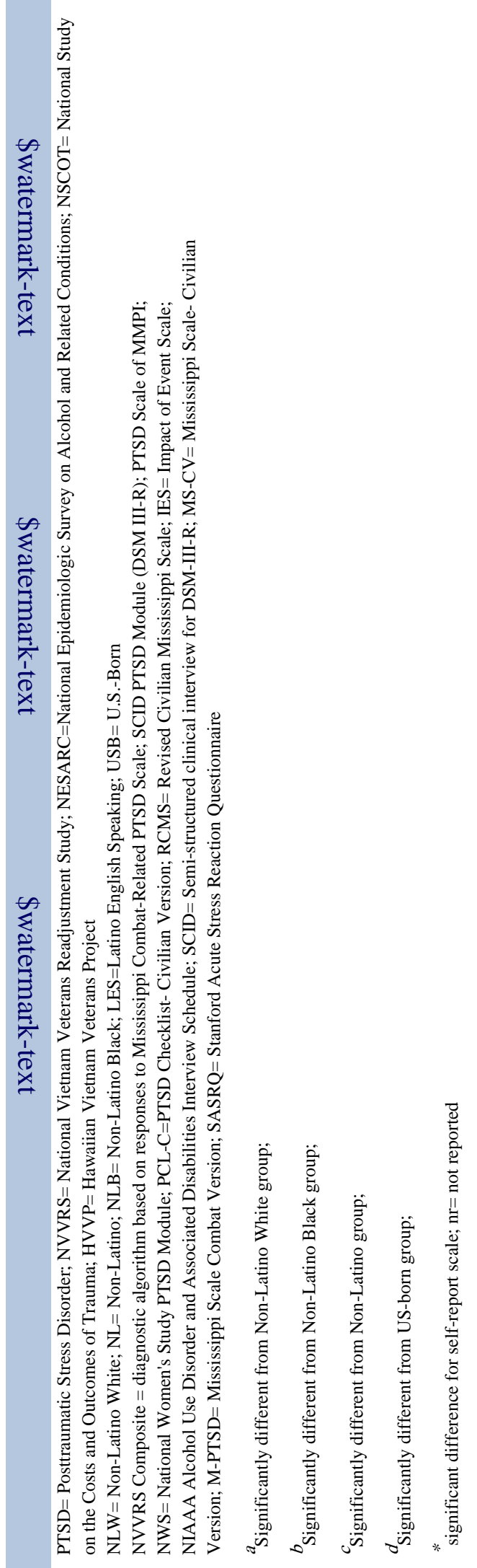

Clin Psychol Rev. Author manuscript; available in PMC 2014 February 01. 
Table 2

Risk of Bias Assessment Across and Within Included Articles $(n=28)$

\begin{tabular}{|c|c|c|c|}
\hline Study by Index Trauma & Selection Bias & Attrition Bias & Reporting Bias \\
\hline \multicolumn{4}{|l|}{ War Combat } \\
\hline Schlenger et al. 1992 & Low & Low & Low \\
\hline Fontana \& Rosenheck, 1994 & Low & Unclear & Low \\
\hline Ortega \& Rosenheck 2000 & Low & Low & Low \\
\hline Koopman et al. 2001 & High & High & Low \\
\hline Schnurr et al. 2004 & Low & Unclear & Low \\
\hline Dohrenwend et al. 2008 & Low & Low & Low \\
\hline Lewis-Fernandez et al. 2008 & Low & Low & Low \\
\hline \multicolumn{4}{|l|}{ World Trade Center Attack (9/11) } \\
\hline Galea et al. 2002 & Low & Unclear & Low \\
\hline Galea et al. 2004 & Low & Low & Low \\
\hline Adams \& Boscarino 2005 & Low & Unclear & Low \\
\hline Adams \& Boscarino 2006 & Low & Unclear & Low \\
\hline DiGrande et al. 2008 & High & Low & Low \\
\hline Galea et al. 2008 & Low & Low & Low \\
\hline Bowler et al. 2010 & High & Unclear & Low \\
\hline \multicolumn{4}{|l|}{ Physical Injury } \\
\hline Denson et al. 2007 & High & Low & Low \\
\hline Zatzick et al. 2007 & High & Low & Low \\
\hline Williams et al. 2008 & High & High & Low \\
\hline Marshall, Schell, \& Miles 2009 & High & Low & Low \\
\hline \multicolumn{4}{|l|}{ Police Duty-Related Trauma } \\
\hline Pole et al. 2001 & High & Unclear & Low \\
\hline Pole et al. 2005 & High & Unclear & Low \\
\hline \multicolumn{4}{|l|}{ Hurricanes Paulina, Andrew } \\
\hline Norris, Perilla, \& Murphy 2001 & High & Unclear & Low \\
\hline Norris, Perilla, Ibanez, et al. 2001 & High & Unclear & Low \\
\hline Perilla, Norris, \& Lavizzo 2002 & High & Unclear & Low \\
\hline \multicolumn{4}{|l|}{ Childhood Abuse } \\
\hline Balsam et al. 2010 & High & High & Low \\
\hline \multicolumn{4}{|l|}{ Lifetime Traumas } \\
\hline Heilemann et al. $2005 \mathrm{~b}$ & High & High & Low \\
\hline Roberts et al. 2010 & Low & Low & Low \\
\hline \multicolumn{4}{|l|}{ Intimate Partner Violence } \\
\hline Rodriguez et al. 2008 & High & Unclear & Low \\
\hline Stampfel et al. 2010 & High & High & Low \\
\hline
\end{tabular}




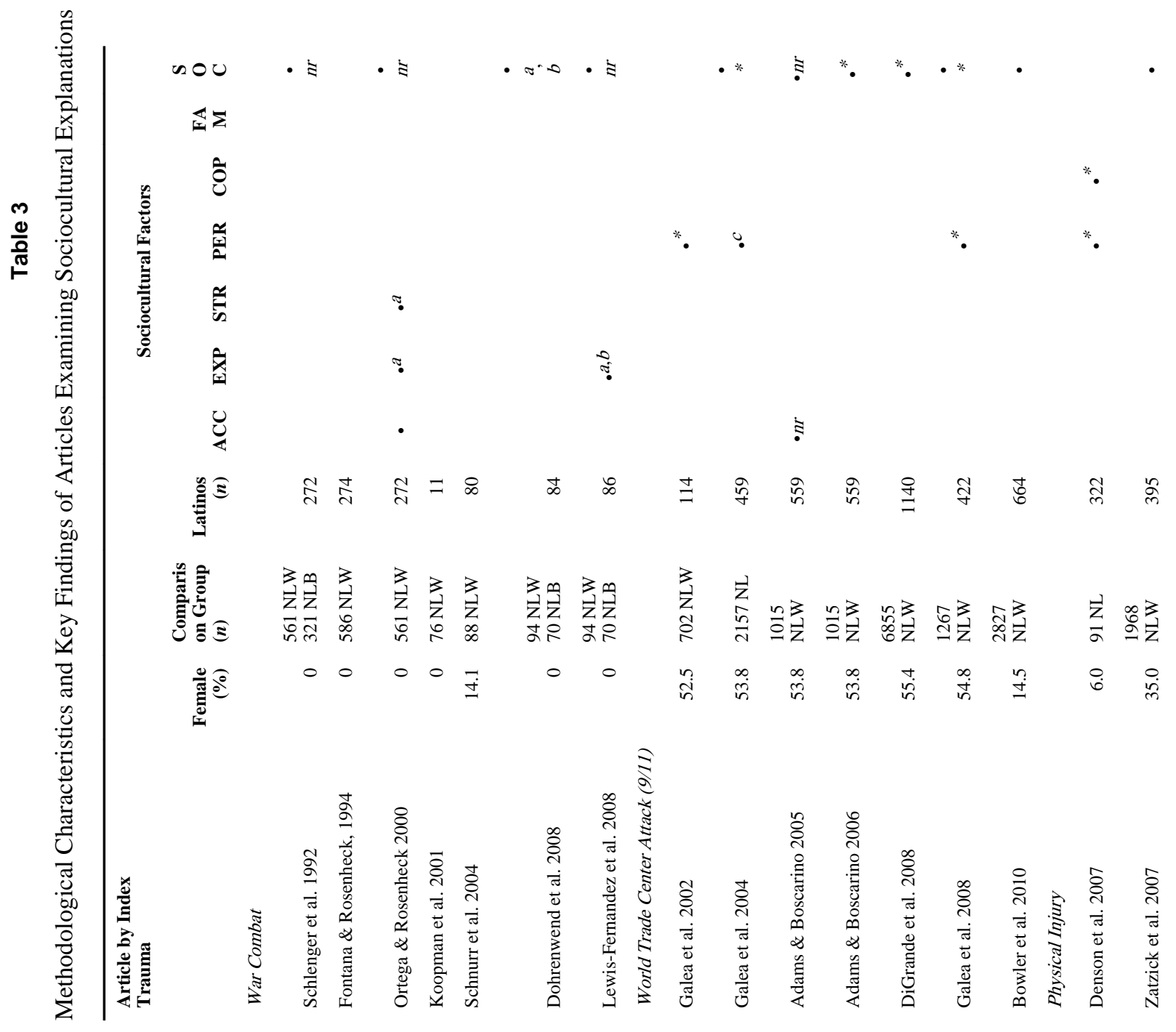




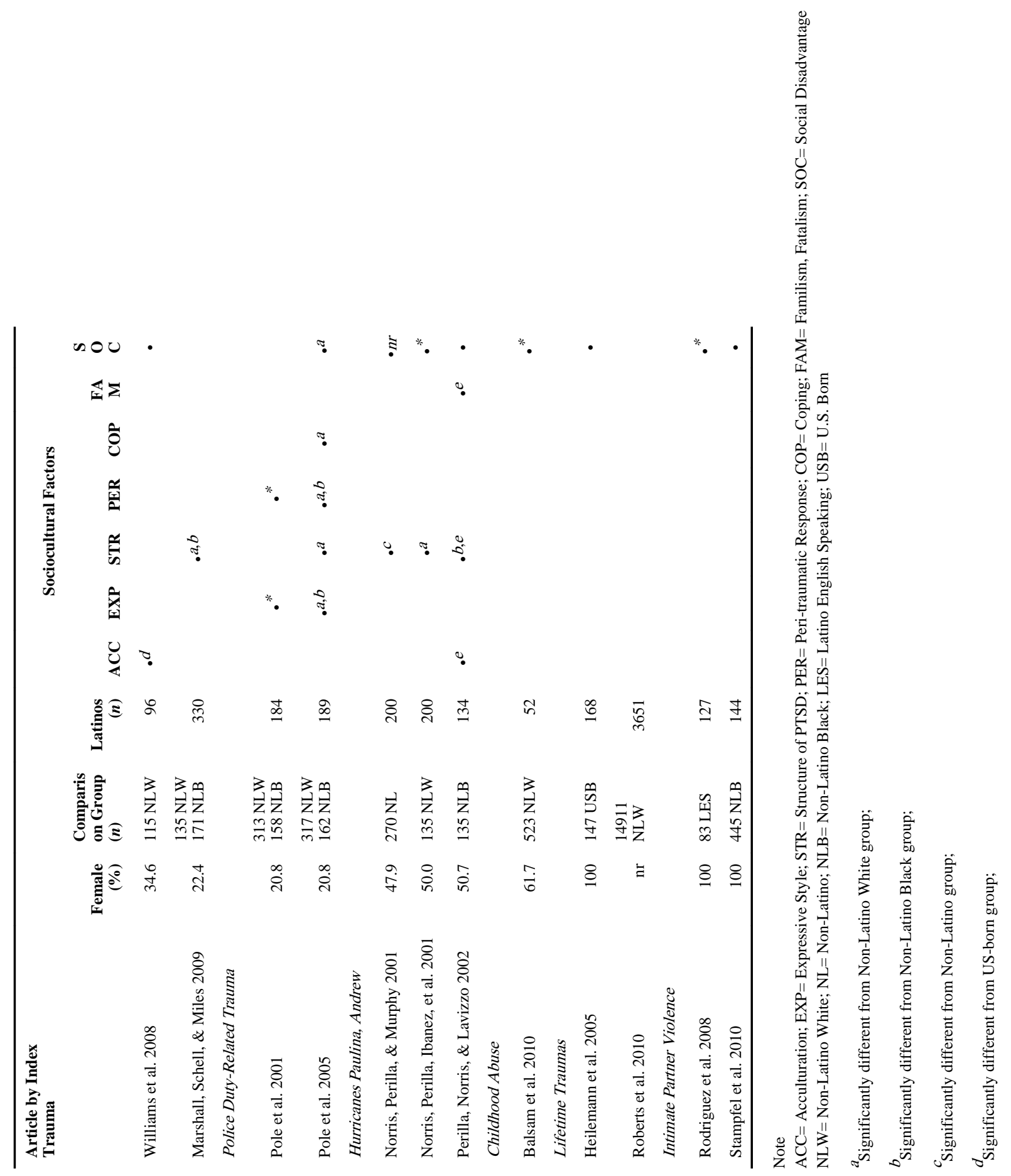




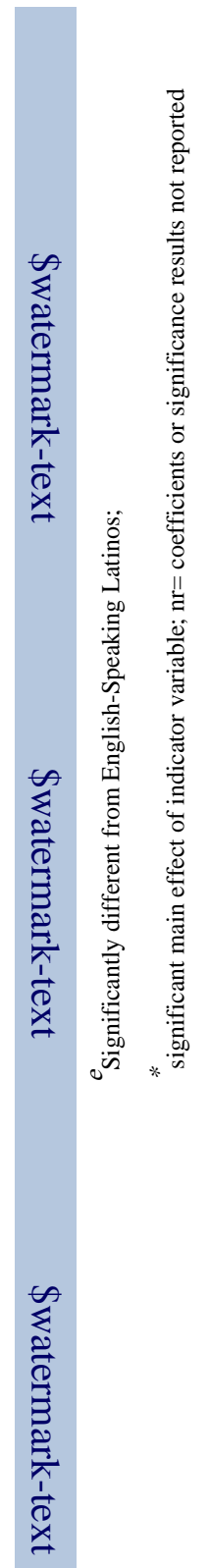

Alcántara et al.

Page 29$$
\text { . }
$$

Clin Psychol Rev. Author manuscript; available in PMC 2014 February 01. 